\title{
A contribuição do cooperativismo de crédito solidário no fortalecimento da identidade territorial: o caso do sistema ASCOOB e sua atuação no território do Sisal, Bahia
}

\section{The contribution of solidary credit cooperativism to the strengthening of territorial identity: the case of the ASCOOB system and its operations in the territory of Sisal,} Bahia

\author{
Ana Claudia Valverde Santos \\ Universidade do Estado da Bahia, Brasil \\ claudiatapuio@gmail.com
}

\begin{abstract}
Resumo:
O cooperativismo é um conjunto de doutrinas que visa essencialmente o desenvolvimento econômico e social, suas práticas vêm de encontro às contradições surgidas com o capitalismo. Assim, a instituição cooperativa surge como uma proposta de superação da desigualdade e exploração. O presente estudo investiga se/como o cooperativismo de crédito solidário contribui no fortalecimento da identidade territorial dentro do Território do Sisal Bahia, mais precisamente com o recorte do município de Serrinha. Para tanto, foi necessário uso de pesquisas bibliográficas que possibilitaram o diálogo com diferentes teóricos que discutem as relações tecidas no território e o levantamento de dados através de entrevistas realizadas com os dirigentes e filiados à ASCOOBSerrinha. O tratamento dessas informações e a revisão bibliográfica permitiu afirmar ao final do estudo que o cooperativismo de crédito solidário é um importante instrumento de inserção social e principalmente de representação identitária.
\end{abstract}

Palavras Chave: Cooperativismo. Economia Solidária. Identidade Territorial. Inserção Social. Representação Identitária.

\begin{abstract}
:
Cooperativism is a set of doctrines that essentially aims at economic and social development, its practices come against the contradictions that arose with capitalism. Thus, the cooperative institution emerges as a proposal to overcome inequality and exploitation. The present study investigates whether cooperativism of solidarity credit contributes to the strengthening of the territorial identity within the Territory of Sisal Bahia, more precisely with the clipping of the municipality of Serrinha. In order to do so, it was necessary to use bibliographical researches that allowed the dialogue with different theorists that discuss the relations established in the territory and the data collection through interviews with the leaders and members of ASCOOB-Serrinha. The treatment of this information and the bibliographic review allowed us to affirm at the end of the study that cooperativism of solidarity credit is an important instrument of social insertion and mainly of identity representation.
\end{abstract}

Keywords: Cooperativism. Solidarity economy. Territorial Identity. Social Insertion. Identity Representation. 


\section{INTRODUÇÃO}

Este trabalho pretende investigar se/como o cooperativismo de crédito solidário contribui no fortalecimento da identidade territorial, analisar as interações sociais engendradas no território a partir da prática do cooperativismo de crédito solidário e compreender o cooperativismo de crédito solidário como instrumento de inserção social e representação identitária.

No decorrer dos estudos teóricos do curso de Pós-Graduação em Gestão de Cooperativas com Ênfase em Economia Solidária, promovido e ministrado pela Universidade do Estado da Bahia em conjunto com a Associação das Cooperativas de Apoio a Agricultura Familiar (ASCOOB) evidenciou-se a importância dos estudos relacionados às práticas cooperativistas, principalmente as engendradas no Estado da Bahia.

Portanto, este trabalho assume relevância, visto que propõe debater a contribuição do cooperativismo de crédito solidário enquanto agente minimizador das contradições do sistema capitalista, principalmente no que tange as classes menos favorecidas. A instituição cooperativa surge não só como uma forma de luta de classes neste sistema, mas também como uma proposta de superação da desigualdade e exploração. Nas palavras de Búrigo (2006, p. 49) “As experiências cooperativistas tentavam colocar em prática as teses dos primeiros utopistas a respeito da criação da sociedade ideal. Nasciam ali, igualmente, as bases para a formulação de um novo modelo econômico, que se dispunha a superar o capitalismo".

O presente estudo é um anseio de interpretação da realidade cooperativa diante do processo de globalização e dos possíveis impactos que a chamada economia solidária pode causar aos sujeitos envolvidos. As reflexões feitas durante o curso de Pós-graduação levaram ainda a percepção de que o espaço reservado na academia ao cooperativismo seja ele de crédito ou não, ainda é um tanto quanto incipiente.

Assim, os resultados obtidos nesta pesquisa contribuem para discussões e compreensões a cerca do protagonismo social dos sujeitos dentro do território. Para tanto, escolheu se trabalhar com o Território do sisal ${ }^{11}$ Bahia, mais precisamente com o recorte do município de Serrinha, assim a pergunta problema que norteia a pesquisa é: De que maneira a atuação da ASCOOB anima a identidade territorial?

A busca por elucidar tal questão leva ao estudo algumas características do recorte analisado, tendo como objetivo central a análise dos impactos do cooperativismo de crédito solidário nas

\footnotetext{
${ }^{1} \mathrm{O}$ Território do Sisal, constituído a partir de políticas de desenvolvimento territorial, é composto por vinte municípios e está inserido no semiárido baiano. Ver decreto 12354/10.
} 
relações socioespaciais e nas representações identitárias no território do sisal através da atuação da ASCOOB.

O presente estudo apresenta-se como sendo de abordagem qualitativa, pois nas palavras de Silva (2001, p. 20) “[...] a pesquisa qualitativa considera que há uma relação dinâmica entre o mundo real e o sujeito, a interpretação dos fenômenos e a atribuição de significados são básicas no processo de pesquisa qualitativa". Assim, a tentativa de compreensão da dinâmica do fenômeno estudado o faz um trabalho de cunho qualitativo.

Salienta-se a importância do método utilizado durante a realização da pesquisa, pois de acordo com Spósito (2004, p. 23) este deve ser abordado "como instrumento intelectual e racional que possibilite a apreensão da realidade objetiva pelo investigador, quando este pretende fazer uma leitura dessa realidade e estabelecer verdades cientificas para sua interpretação”.

A fim de atingir os objetivos esperados trabalhou-se com o método dialético, o qual possibilita compreender qual a relação de causa e efeito entre a atuação da Ascoob no território do sisal e o possível fortalecimento da identidade territorial.

Para alcançar os objetivos definidos para este trabalho o principal instrumento será a análise bibliográfica e coleta de dados por meio de sites e entrevista com membros da organização. Como técnica para obter informações foram realizadas entrevistas com alguns dirigentes da ASCOOB, bem como a uma parcela de associados a instituição.

Ainda como instrumento para facilitar a realização da pesquisa far-se-á o uso da observação semiestruturada. Pois, de acordo com Chizzotti (2001) o uso da observação semiestruturada se faz a fim de perceber a ocorrência de eventos previamente definidos, os quais podem vir a caracterizar melhor o fenômeno estudado. Pretende-se com auxilio da observação, a construção de uma grade a qual após análise permitirá perceber alguns aspectos inerentes ao fenômeno estudado, além de visitas à Ascoob.

No caso desta pesquisa as informações obtidas através da observação servirão para ajudar no conhecimento do universo estudado e de alguns de seus componentes.

Entende-se que a qualidade da pesquisa está diretamente ligada a qualidade de argumentação adquirida ao longo do processo que envolve sua realização. Assim a relação de troca entre sujeito e objeto fica evidente, pois de acordo com Spósito (2004) no método dialético o sujeito se constrói vis a vis o objeto e vice-versa.

É importante ressaltar que a revisão bibliográfica que permeará toda a construção da pesquisa e é um fator relevante para a realização do trabalho, pois antes de lançar um olhar sobre o fenômeno estudado procura-se conhecê-lo.

O arcabouço teórico utilizado na pesquisa também vem a dar subsidio na compreensão do fenômeno estudado. Pois o diálogo com as ideias de autores como Souza (1995), Valadares (2005), 
Haesbaert (2012), Singer (2003) possibilitam a compreensão de como o cooperativismo pode amenizar contradições engendradas nas relações tecidas no território.

Dessa forma, definiu-se como objetivo geral investigar se/como o cooperativismo de crédito solidário contribui no fortalecimento da identidade territorial. Trabalhou-se também com os objetivos específicos, dentre os quais, analisar as interações sociais engendradas no território a partir da prática do cooperativismo de crédito solidário e compreender o cooperativismo de crédito solidário como instrumento de inserção social e representação identitária.

\section{HISTÓRICO DO COOPERATIVISMO}

O cooperativismo é um conjunto de doutrinas que visa essencialmente o desenvolvimento econômico e social, suas práticas vêm de encontro às contradições surgidas com o capitalismo. As cooperativas são definidas de acordo com a Organização Internacional do Trabalho (OIT), como uma: “[...]uma associação autónoma de pessoas unidas voluntariamente para satisfazer aspirações e necessidades económicas, sociais e culturais comuns através de uma empresa de propriedade comum e democraticamente gerida" (OIT, 2006, p.04).

Esse conceito permite perceber a cultura cooperativista como uma forma de promoção social, a qual os sujeitos são protagonistas de seus empreendimentos.

[...] a instituição cooperativista moderna nasceu nos meios populares. Historicamente o cooperativismo moderno surgiu como instrumento de defesa, de reabilitação e de emancipação de trabalhadores, como reação às condições sociais e econômicas adversas originadas da evolução do capitalismo. (VALADARES, 2005, p.06)

No contexto da revolução industrial surgiram as primeiras cooperativas como um contraponto as condições de trabalho engendradas com o advento do capitalismo latente do século XIX. Essas primeiras experiências cooperativas aconteceram na Inglaterra e na França, sendo a primeira cooperativa moderna reconhecida mundialmente a de Rochdale-Manchester, Inglaterra criada em 1844 por 27 tecelões e uma tecelã. Inicialmente essas cooperativas atuavam essencialmente como sociedades beneficentes, só no fim do século XIX o cooperativismo vai abranger outros setores. Para Dorilêo (2007) citado por Giovelli (2012, p.03):

Em virtude da necessidade de sobrevivência, os tecelões buscaram uma alternativa econômica para atuarem no mercado, frente ao capitalismo ganancioso que os submetiam, como os preços abusivos, exploração da jornada de trabalho de mulheres e crianças e o desemprego crescente oriundo da revolução industrial. $\mathrm{Na}$ busca por melhoria de vida e com os objetivos claros e discutidos, os trabalhadores economizaram durante 12 , o equivalente a 28 libras, criaram uma sociedade que meses atuaria no mercado, tendo como finalidade o homem, não o lucro. 
Ainda no século XIX, várias outras experiências surgiram, tais como Schulze-Delitzsch, Raiffeisen e Haas, na Alemanha, Luzzatti e Wollemborg, na Itália. Assim como Rochdale, ambas foram de extrema importância para a consolidação da cultura cooperativista no mundo. Inspiradas nas primeiras experiências, o cooperativismo se expandiu e alcançou diferentes ramos.

No Brasil o movimento cooperativo surgiu no fim do século XIX, com a criação da primeira cooperativa de consumo em Ouro Preto - MG, embora existissem traços de cooperação desde a colonização. Para Búrigo (2006, p. 47):

No Brasil Colônia, os negros fugitivos organizaram quilombos em várias partes do país, que funcionaram como repúblicas cooperativas. Os jesuítas, que aportaram no continente sul americano no início do século XVII, aliaram a prática do mutirão - um tipo de cooperação indígena - com a fé cristã, para organizarem as missões coletivistas. A "República dos Guaranis" funcionou por cerca de 150 anos como um modelo original de organização econômica e social.

Já no século XX, surgiram as primeiras cooperativas de crédito no Rio Grande do Sul, nessa região surgiram também as primeiras cooperativas rurais fundadas por imigrantes, as cooperativas fundadas em Ouro Preto serviram de inspiração para a difusão do cooperativismo em diferentes estados do Brasil.

\footnotetext{
No Brasil, as demonstrações formais do cooperativismo só puderam ser registradas com o advento da República, e da Lei Magna de 1891. Até então, o associativismo era tão mal visto pelas autoridades que a proibição das práticas cooperativas era oficial e estava inserida na Constituição monarquista de 1824. Com a abertura republicana, a primeira cooperativa brasileira - que era do ramo do consumo - foi organizada por empregados públicos de Ouro Preto - MG. Depois surgiram outras cooperativas de consumo em Limeira - SP em 1891, no Rio de Janeiro - RJ em 1894, em Camaragibe - PE em 1895 e em Campinas - SP no ano de 1897. Em 1892 é fundada a primeira cooperativa de produtores rurais, na região gaúcha de Veranópolis e Antônio Prado. (BÚRIGO, 2006. p.57)
}

A difusão do cooperativismo no país pode ser observada na criação da Organização das Cooperativas Brasileiras (OCB) em 1969, e na instituição da Lei 5.764 de novembro de 1971 que dispõe sobre o regime jurídico das cooperativas. Embora a lei 5.764/71 tenha disciplinado a criação de cooperativas, ela é vista como um entrave devido as suas restrições à autonomia das sociedades cooperativas.

Antes da 5.764/71 as cooperativas eram vistas como sociedade de pessoas instituídas por decreto $\mathrm{n}^{\circ} 22.239 / 32$ do presidente Vargas, na época as cooperativas recebiam incentivos do governo, através da isenção de impostos, pois eram vistas como um meio de geração de renda e difusão da educação através de seus princípios associativos. Alguns anos depois com a criação do Banco Nacional de Crédito Cooperativo (BNCC), em 1951, o governo passa a intervir de maneira mais direta nos recursos direcionados ao cooperativismo. Essa intervenção só aumentaria com o passar dos anos, culminando na lei 5.764/71. 
Em 1964, ao ganhar a primeira política nacional de cooperativismo, o País oficializava também a intervenção estatal no setor. As medidas foram incluídas no Estatuto da Terra (Lei $n^{\circ}$ 4504), que concedia ao Instituto Nacional de Colonização e Reforma Agrária, na época ainda ligado ao Ministério da Agricultura, Pecuária e Abastecimento (MAPA), as funções de normatizar, registrar e fiscalizar o funcionamento das cooperativas e das associações rurais. Apenas os ramos de crédito e habitacional não estavam incluídos, pois eram controlados pelo Banco Central e pelo extinto Banco Nacional de Habitação, respectivamente. (BRASIL, 2006, p. 22)

Nos anos em que o Brasil viveu sob a ditadura militar o controle do estado sobre os diferentes ramos do cooperativismo só aumentou, no entanto, com a abertura democrática e a constituição de 1988, os setores ligados ao cooperativismo conseguiram várias conquistas. Dentre elas, a independência das cooperativas que passaram a atuar sem o controle do Estado, porém, o ramo crédito permaneceu sobre o controle do Banco Central, mesmo com vários projetos que visam diferencias este ramo das demais instituições financeiras.

A Constituição Federal de 1988 promoveu avanços frente à Lei no 5.764 , de 1971, mas a evolução do setor exige novas alterações. O Projeto de Lei $\mathrm{n}^{\circ} 171$, que trata sobre o setor e foi apresentado em 1999, tramita no Congresso Nacional, juntamente com um substitutivo, apresentado pela Casa Civil da Presidência da República em abril de 2006. Foram apensados ainda o Projeto de Lei $n^{\circ} 605$ e o Projeto de Lei $n^{\circ} 450$. Outros projetos de lei sobre cooperativismo ainda tramitam no Congresso, mas tratam de ramos específicos, como o de trabalho e o de crédito. (Ibid, p. 23).

A expansão do cooperativismo pelo Brasil segue as contradições iminentes do sistema capitalista, pois a centralização promovida através da OCB esteve historicamente ligada à promoção do agronegócio através dos subsídios promovidos pelo governo com vistas de modernizar a agricultura. Em contraponto, o caráter de luta e solidariedade ficou distante da OCB quando muitas cooperativas foram liquidadas por não atenderem aos objetivos centralizadores da instituição.

\begin{abstract}
A falta de identidade entre os mandatários cooperativistas brasileiros e as lutas populares ficou mais patente depois do surgimento da OCB. Fundada em 1969, a OCB foi concebida para "pacificar" e centralizar, numa instância única, as diferentes forças que atuavam junto ao cooperativismo nacional naquele momento. A partir da hegemonia dos produtores rurais e sob a tutela do Governo Militar, a OCB conseguiu - através principalmente da criação da Lei 5.764, de 1971, e do apoio do Ministério da Agricultura - canalizar investimentos consideráveis e privilégios fiscais às suas filiadas, especialmente às cooperativas agropecuárias (coopers) de maior porte. Grande parte dessas ações integrava-se aos projetos de criação e fortalecimento de complexos agroindustriais, tendo plena consonância com as políticas de modernização (conservadora) do meio rural brasileiro. Tais mudanças na agricultura brasileira foram implantadas com ajuda de programas de crédito subsidiado e dos órgãos de assistência técnica governamental. Em muitos casos esses programas também eram operados pelas próprias cooperativas. (BÚRIGO, 2006. p.57-58)
\end{abstract}

As mudanças trazidas com a constituição de 1988 faz com que muitas cooperativas não aceitem a OCB como representatividade única da classe, devido a sua histórica atuação contraditória frente às lutas de classe. Embora, a OCB por meio da OCEs ainda articule várias 
cooperativas, e influencie muitas leis cooperativistas em diversos estados, o que se vê no Brasil é o surgimento de um grande leque de movimentos independentes da OCB.

\begin{abstract}
A Organização das Cooperativas do Brasil, a OCB, monopoliza hoje a representação do cooperativismo brasileiro. Na época do regime militar, a OCB era praticamente estatal. Hoje ela é uma associação voluntária privada, que assumiu a curiosa forma de sindicato. A OCB é um sindicato de cooperativas. E ela se registrou como sindicato patronal; ninguém sabe disso porque não tem importância pública. A OCB adotou essa atitude para poder criar o Serviço Social das Cooperativas (Sescoop). Para tanto, eles tiveram que se adaptar à Lei do Serviço Social, segundo a qual só os sindicatos patronais é que geram os Sesi, Sesc, Senai, Senac. Então hoje temos o Sescoop, que presta serviços às cooperativas, embora seja sustentado por contribuições sobre a folha de pagamento de cada cooperativa. Em analogia com as demais entidades do sistema "S", o Sescoop teria de prestar serviços aos empregados das cooperativas. (SINGER, Apud a OLIVEIRA, 2007, p.13)
\end{abstract}

Um desses movimentos que atuam independentes da OCB é a União Nacional das Cooperativas de Agricultura Familiar e Economia Solidária (UNICAFES), fundada em 2005, com representatividade nacional, atua nas cinco regiões com aproximadamente 1.100 cooperativas em diferentes ramos de atividades.

Diante dessa contextualização histórica, cabe ressaltar que com o passar dos anos o cooperativismo evoluiu no âmbito econômico, em detrimento do papel social, acompanhando a expansão do modo de produção capitalista, o que fez com que alguns de seus princípios fossem deixados de lado. Assim algumas cooperativas passaram a ter um perfil de empresa capitalista, deixando o seu caráter social de lado.

Em contraponto a essa descaracterização do movimento cooperativista no Brasil, surge no final do século XX, vinculada a movimentos sociais e entidades vinculadas a sociedade civil como as igrejas, a chamada economia solidária.

[...] A economia solidária surge como modo de produção e distribuição alternativo ao capitalismo, criado e recriado periodicamente pelos que se encontram (ou temem ficar) marginalizados do mercado de trabalho... A economia solidária é uma criação em processo contínuo de trabalhadores em luta contra o capitalismo. [...] (SINGER, 2003. p. 13)

Na economia solidária os princípios do cooperativismo estão em consonância com o que foi proposto quando do surgimento das lutas de classe, onde o que se propõe é que os trabalhadores tenham, sobretudo igualdade de oportunidades frente à economia capitalista.

A economia solidária é vista aqui como uma categoria genérica, já que além das experiências do tipo cooperativo são incluídas nesse conceito as que se autodenominam de economia social, socioeconomia solidária, humanoeconomia, economia popular e solidária, economia de proximidade, economia de comunhão, práticas de reciprocidade etc. Nota-se, sem embargo, que uma das principais características que unem os empreendimentos envolvidos é a sua disposição para participar, de algum modo, dos mercados, ainda que seus protagonistas não pautem seus negócios pela lógica capitalista do lucro máximo (BÚRIGO, 2006. p.161). 
Desta maneira, os empreendimentos de economia solidária são hoje protagonistas das relações que vão de encontro ao sistema vigente.

No estado da Bahia o movimento cooperativista surge atrelado a lutas de classe, seguindo a tendência nacional, muitas cooperativas despontaram por meio das reivindicações de movimentos sociais organizados ainda na época da ditadura militar.

No entanto em nível de estado o cooperativismo só alcançou um marco legal em 2009 com a instituição da Política Estadual de Apoio ao Cooperativismo. O que se vê tanto na Bahia como no Brasil é que muitas mudanças ocorreram fazendo com que a expressão maior da economia solidária seja organização dos trabalhadores em cooperativas. Assim para entender o papel dos atores sociais através das cooperativas, é necessária a compreensão das relações no âmbito do território.

\section{IDENTIDADE E TERRITÓRIO}

Para o desenvolvimento do presente estudo fez-se necessário algumas considerações acerca do território, para muitos estudiosos da ciência geográfica esse conceito não deve ser reduzido ao espaço de atuação nacional, como é corriqueiro no senso comum se referir ao território apenas como território nacional. Para Souza (1995, p. 81): “[...] ele não precisa e nem deve ser reduzido a essa escala ou à associação com a figura do Estado. Territórios existem e são construídos (e desconstruídos) nas mais diversas escalas, da mais acanhada (p.ex, uma rua) à internacional [...]”.

No campo da ciência geográfica são vários os estudos sobre o território, porém de acordo com Haesbaert (2012, p. 42):

[...]Somos levados, mais uma vez, a buscar superar a dicotomia material/ideal, o território envolvendo ao mesmo tempo, a dimensão espacial material das relações sociais e o conjunto das representações sobre o espaço ou o "imaginário geográfico" que não apenas move como integra ou é parte indissociável destas relações[...].

O presente trabalho não pretende tecer uma discussão epistemológica acerca do território, no entanto corrobora-se com as ideias de Haesbaert no que diz respeito à forma de abordagem, este conceito não deve ser simplificado, a uma perspectiva natural, ou política e até mesmo cultural.

[...] o território no sentido relacional com que trabalhamos, não é simplesmente uma "coisa" que se possui ou uma forma que se constrói, mas, sobretudo uma relação social mediada e moldada na/pela materialidade do espaço. Assim, mais importantes do que as formas concretas que construímos são as relações com as quais nós significamos e "funcionalizamos" o espaço, ainda que num nível mais individual [...] (HAESBAERT, 2012. p.350)

O território, embora seja genericamente definido nas palavras de Souza (1995) como: “um espaço definido e delimitado por e a partir das relações de poder", é um dos elementos que, vem a 
facilitar a concepção da organização e planejamento das relações tecidas no espaço geográfico, visto sua complexidade e amplitude de aplicação dentro dos diferentes setores da sociedade atual.

Dentro de uma visão mais ampla o território não é facilmente definido, no entanto nas palavras de Haesbaert (2012, p. 341) numa perspectiva mais integradora:

[...] devemos priorizar assim a dinâmica combinada de múltiplos territórios ou "multiterritorialidade"... Essas dinâmicas se desdobram num continuum que vai do caráter mais concreto ao mais simbólico, sem que um esteja dicotomicamente separado do outro. No caso de um individuo e/ou grupo social mais coeso, podemos dizer que eles constroem seus (multi) territórios integrando, de alguma forma, num mesmo conjunto, sua experiência cultural, econômica e política em relação ao espaço.

Partindo de tais ideias, pode se afirmar que a apropriação de um território por determinado grupo social gera identidades. Embora a construção de identidades seja vista simbolicamente, sua discussão é essencial na sociedade contemporânea, na medida em que fornece elementos de compreensão da mesma. Para Haesbaert (2011), em seu artigo intitulado "o espaço importa: dilemas da construção identitário-territorial na contemporaneidade" na construção dos processos sociais existe uma relação intrínseca entre identidade e espaço/território.

[...] toda identidade, a exemplo de qualquer processo social, tem uma dimensão espacial pelo simples fato de não se realiza puramente "em abstrato", mas contextualizada no espaço-tempo, geográfica e historicamente percebido/vivido. [...] toda identidade é também “espacial” [...] (HAESBAERT, 2011. p.51).

A questão da identidade é debatida por muitas ciências, abordam esse conceito sobre diferentes óticas, no entanto o que se percebe é que nas ciências há um enfoque para a relação entre identidade e sociedade, como enfatizam Braga; Abreu (2011, p. 77):

Nas últimas décadas, estudos a partir de diversas áreas e perspectivas passaram a enfatizar a relação entre a constituição de identidades e a participação em práticas sociais e discursivas [...]. Abrem-se novos horizontes para as investigações nas ciências humanas e sociais, conduzindo à centralidade da linguagem e do discurso sobre a relação entre individuo/sociedade.

A complexidade que permeia a questão identitária está relacionada ao individuo enquanto singular e também plural, ente sujeito/objeto da sociedade em determinado tempo e espaço. Hetherington (1998) apud Haesbaert (2011, p. 52):

Identidade diz respeito tanto a similaridade quanto a diferença. Diz respeito ao modo como sujeitos veem a si mesmos em representação e a como eles constroem diferenças dentro daquela representação e entre esta e a representação de outros. Identidade diz respeito tanto a correspondência quanto a dissimilaridade. Fundamentalmente a identidade é articulada através da relação entre pertencimento, reconhecimento e identificação. [...] A formação da identidade como um processo de identificação é um processo espacialmente situado. 
Dessa maneira, a construção da identidade se territorializa no espaço por meio das relações sociais que são construídas, representadas e reconhecidas nele, por determinado grupo social.

Ainda corroborando com as ideias de Haesbaert (2011) onde este afirma que a produção social das identidades territoriais perpassa desde fundamentos materiais até simbólicos e vice-versa. Percebe-se que as relações identitárias tecidas no território, tanto podem ser construídas a partir do que efetivamente é vivido pelos sujeitos do território, ou seja, seus habitantes como podem ser forjadas a partir de simbologias materiais criados para delimitar não só o espaço, mas a identidade territorial dos sujeitos.

Partindo de tais considerações, percebe-se que a identidade territorial, quando forjada para atingir os objetivos de determinado grupo social, por vezes não representa um quantitativo do que é vivenciado na realidade, o que não anula sua representatividade e eficácia.

\section{A CRIAÇÃO DE TERRITÓRIOS DE IDENTIDADES NA BAHIA}

O território baiano é historicamente marcado pela expressão das desigualdades no que tange ao desenvolvimento regional. Léda (2010) "afirma que o processo de configuração territorial da história baiana vincula-se às descontinuidades cíclicas do desenvolvimento capitalista no Brasil”. As quais, vinculadas aos interesses econômicos de oligarquias vigentes em determinados períodos da história fizeram surgir áreas mais atrativas em detrimento de outras no que diz respeito ao crescimento econômico, e desenvolvimento social da população.

Para Léda (2010, p. 35), podem-se indicar três grandes períodos para entender a organização espacial da Bahia e as possíveis tendências de reordenamento territorial.

O primeiro período abrange as configurações territoriais pretéritas da velha Bahia agroexportadora, que se desenvolvem lentamente e predominam no largo curso da história colonial [...] O segundo período, marcado pela transição da velha Bahia agrária para a nova Bahia urbana e industrial, sob condições que combinavam aspectos econômicos e políticos em âmbito nacional e seus desdobramentos e interações regionais[...] O terceiro grande período, iniciado em meados do século XX, a partir do divisor de águas representado pela implantação da indústria petrolífera na Bahia [...]

Embora a dinâmica espacial no que se refere às características das estruturas produtivas, tenha passado por significativas mudanças o que se percebe é que o território baiano ainda passa por inúmeros problemas como afirma o autor anteriormente citado:

[...]o quadro socioeconômico mostra que a Bahia continua a padecer dos problemas estruturais do passado e que se reproduzem num contexto de modernização das bases econômicas. Tais resultados refletem a concentração espacial dos investimentos produtivos e das infraestruturas sociais em áreas restritas do estado. (LÉDA, 2010. p. 38-39) 
Partindo dessas considerações nota-se que existe na Bahia uma heterogeneidade territorial que foi construída historicamente gerando as chamadas desigualdades regionais, nesse contexto o governo do Estado da Bahia, tentando mitigar as diferenças regionais, propôs uma nova regionalização de seu território, que nas palavras de Duarte (2009, p. 02):

Difere da divisão regional estabelecida pelo IBGE (Instituto Brasileiro de Geografia e Estatística), que corresponde a micro-regiões geográficas, ou organizadas como regiões econômicas (ex.: Região Sudoeste da Bahia), que norteavam a ação governamental e se constituíam na base para a formulação de políticas públicas e organização de dados estatísticos. Esta delimitação de região a partir da dimensão econômica segue um eixo norte-sul (ex.: vincula cidades que tem como base o comércio e a pecuária como atividade mais forte, como as micro-regiões geográficas de Vitória da Conquista, Jequié, Itapetinga). Já a noção de Territórios de Identidade segue um eixo leste-oeste (ex.: do Planalto da Conquista à Serra Geral e Chapada Diamantina Meridional) estruturada mais a partir laços cotidianos, do fluxo de pessoas em busca de serviços e as relações comerciais.

Essa proposta visa direcionar os investimentos e estratégias a partir de prioridades definidas em consonância com a realidade local, desta maneira através do decreto 12354/10 institui os territórios de identidades:

Art. $1^{\circ}$ - Fica instituído o Programa Territórios de Identidade, com a finalidade de colaborar com a promoção do desenvolvimento econômico e social dos Territórios de Identidade da Bahia, em consonância com os programas e ações dos governos federal, estadual e municipal.

$\S 1^{\circ}$ - Considera-se Território de Identidade o agrupamento identitário municipal formado de acordo com critérios sociais, culturais, econômicos e geográficos, e reconhecido pela sua população como o espaço historicamente construído ao qual pertence, com identidade que amplia as possibilidades de coesão social e territorial. (GOVERNO DO ESTADO DA BAHIA, 2010)

Dessa maneira foram reconhecidos 27 territórios de identidades (Figura 1), através da Secretaria de Planejamento do Estado da Bahia (SEPLAN). Esses territórios foram agrupados levando-se em consideração as especificidades locais de cada região. A proposta do governo do estado visa promover o desenvolvimento territorial a partir das características das relações que são tecidas dentro de cada território. Para Léda (2010) “ essa tendência de reordenamento regional, expressa uma geografia histórica, das intervenções governamentais no território baiano. 


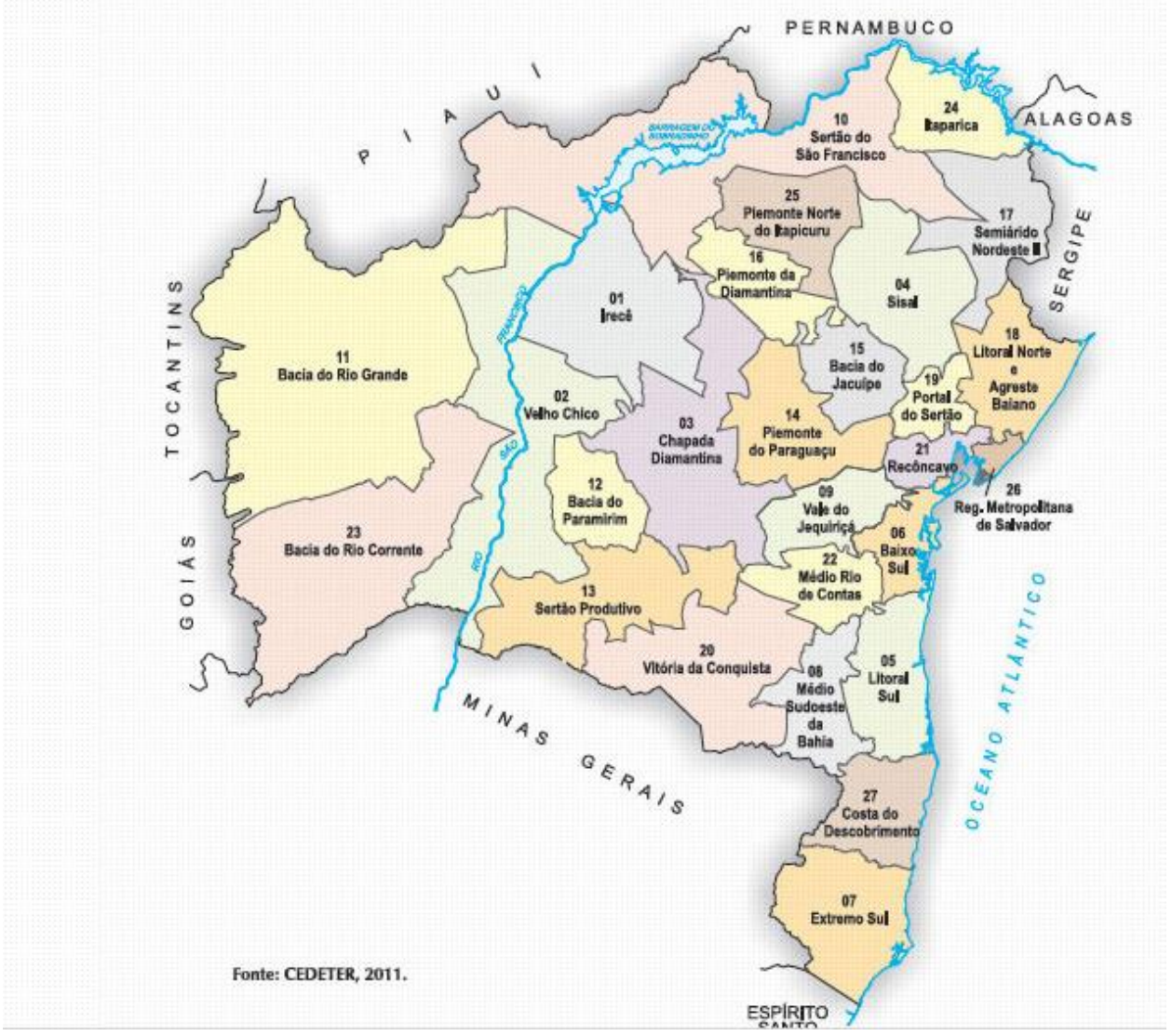

Figura 1 - Territórios de Identidade na Bahia Fonte: CEDETER, 2011.

\section{O TERRITÓRIO DO SISAL E A ASCOOB}

O Território do Sisal, constituído a partir de politicas de desenvolvimento territorial a nível Estadual e Federal, é composto por vinte municípios e está inserido no semiárido baiano. Uma das fortes prerrogativas desse território é participação de movimentos de cunho social (ONGs, associações, cooperativas), os quais contribuíram para o reconhecimento deste, como território de identidade do sisal (Figura 2).

Essas organizações sociais se fazem presente no território desde o período em que o Brasil passou pela ditadura militar, sendo no fim desta, o território protagonista da primeira reivindicação por melhores condições.

Dentro do contexto de busca por melhorias no território do sisal, no que tange a população mais carente, composta em sua maioria por agricultores, surge a ASCOOB, (Associação das Cooperativas de Apoio a Agricultura Familiar). 


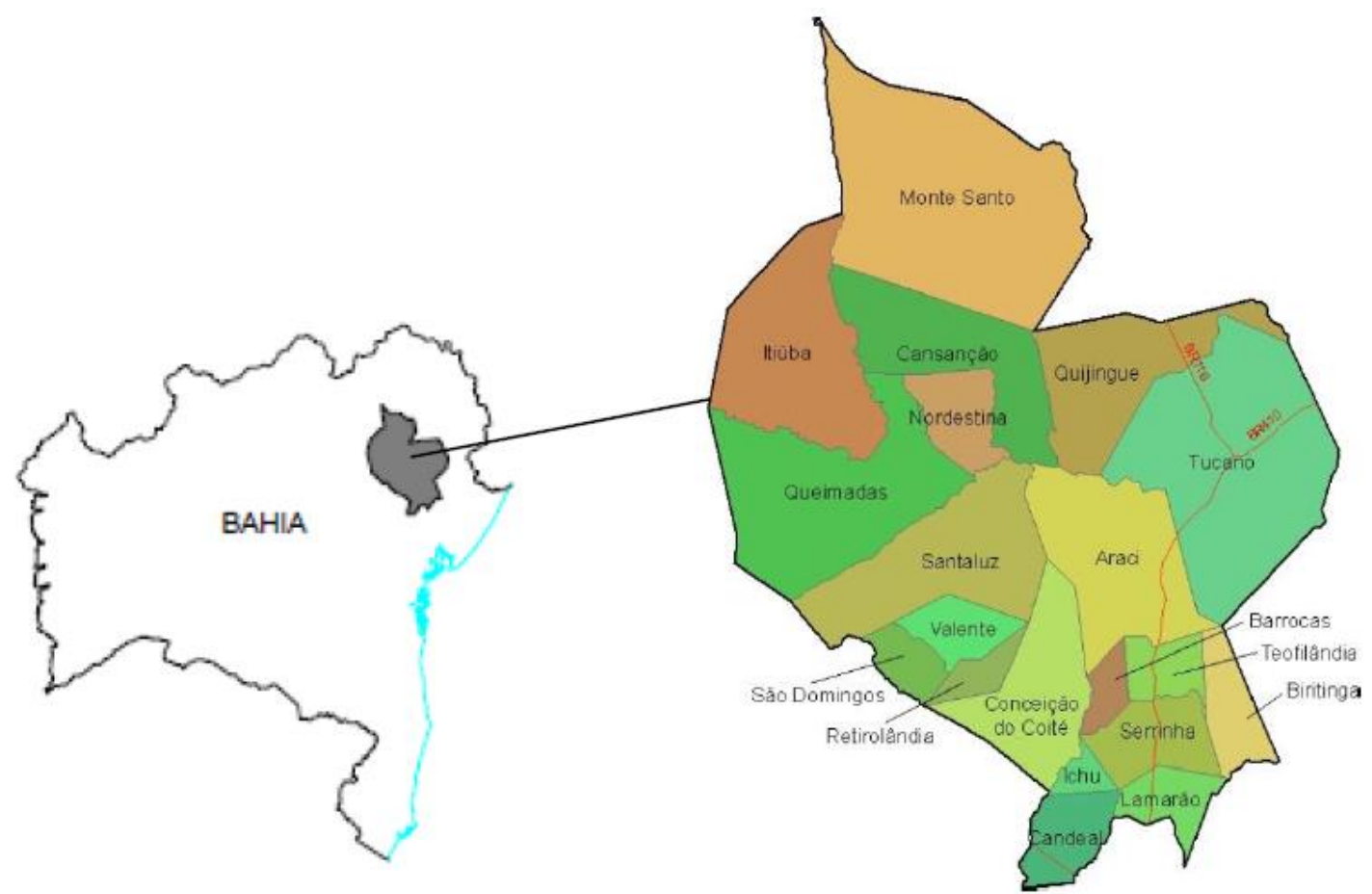

Figura 2: Localização da área de estudo - Território

Fonte: Adaptado do PTDRS Sisal, 2010.

A ASCOOB foi criada em 1999 com o apoio das entidades ligadas aos movimentos sociais do estado da Bahia, com o objetivo de unir forças para o cumprimento dos princípios do cooperativismo de crédito, tendo por base o fortalecimento da economia familiar rural. Magalhães (2005) apud Carvalho (2011, p.17):

Em 1999, 05 cooperativas de crédito rural criaram a Associação das Cooperativas de Apoio a Economia Familiar (Ascoob), uma organização regional com objetivo de fortalecimento da capacidade de gestão das cooperativas de crédito, através de atividades de capacitação e assessoria, financiamento de novas cooperativas, fortalecer a capacidade de negociação das cooperativas por recursos externos e representatividade das cooperativas nas articulações regionais. O complexo formado por 11 cooperativas de crédito rural e 16 postos de atendimento cooperativo passaram a abranger, no ano de 2003, 27 municípios da região sisaleira.

Ao longo de sua atuação a ASCOOB tem priorizado atividades que visem principalmente a melhor aplicação de recursos direcionados a agricultura familiar.

Desde então a ASCOOB desempenha a função de pensar coletivamente questões comuns a todas as cooperativas, principalmente a melhor sistematização do crédito e negociações de recursos para o fortalecimento da agricultura familiar. Para isso, firma parcerias com o Banco do Brasil, Banco do Nordeste e atua a nível nacional juntamente com a Associação do Cooperativismo de Economia Familiar e Solidária (ANCOSOL), Confederação Nacional das Cooperativas Centrais de Crédito e Economia Familiar e Solidária (CONFESOL), União Nacional de Cooperativas da Agricultura Familiar e Economia Solidária (UNICAFS) e Cooperativa de Crédito Rural de Poço Verde - ASCOOB COOPEC. (ASCOOB, 2008. p.01)

Diante da demanda de uma representação legal para as cooperativas filiadas à Ascoob, é criada a Cooperativa Central de Crédito da Agricultura Familiar e Economia Solidária da Bahia 
(ASCOOB Central), em 25 de janeiro de 2008. Esse fato marca o afastamento das cooperativas filiadas a Ascoob do dito cooperativismo tradicional vinculado a OCB, e o fortalecimento da economia solidária, visto que a nova instituição tem como prerrogativa maior a promoção do crédito solidário.

Desde a sua fundação a ASCOOB Central assumiu sua missão de organizar, coordenar e fomentar o Cooperativismo de Crédito, promovendo a inclusão social através da provisão de produtos e serviços financeiros e educativos. Onde se destacam os avanços nas políticas de auditoria, supervisão, gestão e controle, normatização de procedimentos sistêmicos, bem como, na consecução de importantes projetos institucionais com entidades parceiras. Desde então, tem alcançado o seu estágio de maturidade institucional tendo como consequência uma maior profissionalização da gestão e da atividade cooperativista, atendendo as demandas e necessidades financeiras dos seus cooperados. (Ibid. P. 02)

Com a fundação da Ascoob central, a entidade passa atuar na categoria de sistema onde amplia o seu leque de abrangência pelo território da Bahia, chegando também a outros estados como Alagoas e Sergipe. Segundo a mesma são 16 territórios vinculados ao sistema que atua na Gestão, educação Cooperativista, assistência técnica rural, dentre outros serviços que visam a melhoria de suas cooperativas filiadas, abrangendo um total de 50 mil filiados.

Assim sendo para atingir os objetivos do presente artigo, faz-se necessário um recorte na área de estudo para melhor compreensão dos fenômenos estudados.

\section{IMPACTOS DA ASCOOB NA IDENTIDADE TERRITORIAL: A Ascoob Serrinha}

Serrinha é um município do estado da Bahia, localizado no semiárido baiano de clima predominante subsumido a seco, localizada a uma altitude 379 metros do nível do mar e $180 \mathrm{~km}$ de Salvador. Com população estimada de 82.733 segundo informações do Instituto Brasileiro de Geografia e Estatística, 2014 (IBGE), situa-se na Mesorregião Nordeste Baiano e Microrregião de serrinha, o município está inserido no Território de Identidade do Sisal.

Segundo a Superintendência de Estudos Econômicos e Sociais da Bahia, 2014 (SEI), o município conta com três agências bancárias federais e duas privadas, além de concentrar a sede administrativa regional de vários órgãos públicos tais como: núcleo regional de educação, diretoria regional de saúde, entre outros.

O município tem como uma de suas principais atividades econômicas a agricultura, principalmente a chamada agricultura familiar, dentro desse contexto a missão da Ascoob sisal é fortalecer a economia familiar através do cooperativismo de crédito, fomentando os processos de desenvolvimento local integrado, sustentável e solidário, através da inclusão financeira em sua base social, situada na região sisaleira da Bahia. 
Vale salientar que a cooperativa surgiu inicialmente em 1991 com o nome de COOCRESE Cooperativa de Crédito Rural de Serrinha- 1tda. Sendo esta, integrada a CREDIBAHIA (sistema que centralizava as cooperativas no estado) em 1992, a expansão do movimento cooperativista levou a várias mudanças no cenário nacional e consequentemente no baiano.

A integração da COOCRESE no SICOOB- central foi algo árduo devido ao momento de reformulação pelo qual a cooperativa passava nesse período movimentos sócias como o MOC Movimento de Organização Comunitária, o sindicato de trabalhadores rurais, os movimentos de mulheres tiveram atuação importante na reformulação dos princípios de gestão da cooperativa. Salienta-se que a COOCRESE surgiu ligada a uma cooperativa de base patronal. Já em 2000 a cooperativa passa a se chamar SICOOB - Serrinha e é integrada ao sistema.

A criação da Ascoob leva a cooperativa de Serrinha a filiar-se a mesma como vistas a fortalecer o crédito rural ainda no sistema Sicoob, porém a aprovação do Banco Central para que a ASCOOB atue como uma cooperativa central, faz com que o SICOOB - Serrinha filie -se a mesma e adote o nome de ASCOOB SISAL- Serrinha.

A ASCOOB- Serrinha conta com quatro agências sendo elas localizadas em Serrinha, Ichu, Barrocas e Salgadália somando aproximadamente sete mil sócios.

A cooperativa tem sua atuação voltada para a área rural, desta maneira trabalha com o crédito rural, microcrédito, PRONAF, entre outros. Isso faz com que várias associações e grupos de produção estejam associados a ela.

Nas entrevistas que foram realizadas com os dirigentes destas entidades foi relatado que uma média de 50 associações e/ou grupos de produção estão ligados ASCOOB SISAL. O acompanhamento desses grupos fica a cargo dos departamentos de micro finanças e educação por meio de palestras com temas ligados ao associativismo. (Figura 03).

Como verifica-se na figura anterior uma dessas associações ligadas à cooperativa é a Associação Comunitária dos Moradores do Povoado de Alto de Fora - ACMPAF, fundada no ano de 1996, conta atualmente com uma média de cento e quarenta sócios, segundo dados da própria associação. Dentre os objetivos principais da entidade estão: fortalecer a organização econômica, social e política da comunidade, garantindo os direitos dos associados junto ao poder público principalmente no que se diz respeito a, educação, saúde, habitação, transporte e lazer; Racionalizar as atividades econômicas, desenvolvendo formas de cooperação que ajude na produção e comercialização.

Ainda durante entrevista aos dirigentes, os mesmos relataram que a ASCOOB promove por meio do departamento de educação cursos ligados ao cooperativismo e associativismo. 


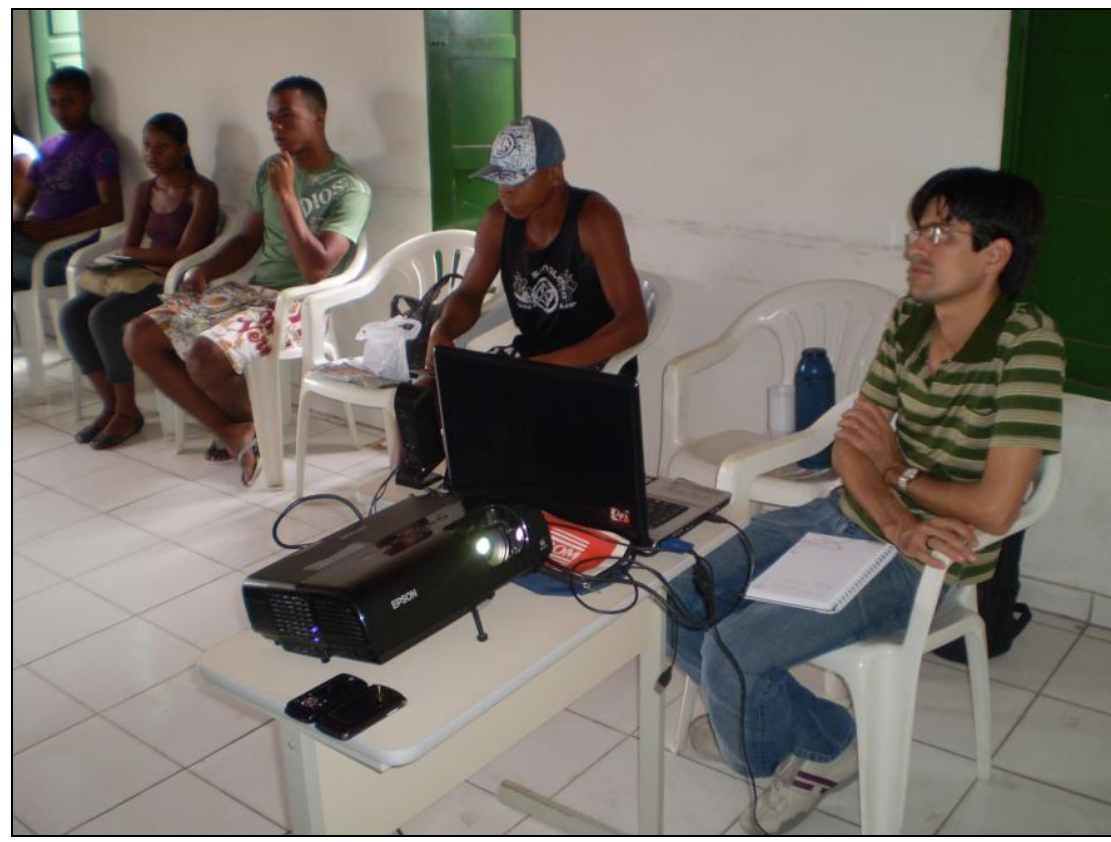

Figura 3: Curso de empreendedorismo promovido pela Ascoob - Serrinha na Associação Comunitária dos Moradores do Povoado de Alto de Fora.

Fonte: ACMPAF, 2015.

Com relação aos grupos que acessam crédito na cooperativa, ficou claro que o incentivo para a produção de produtos locais é o diferencial da ASCOOB criando laços de identidade local (Figura 4). Como relata o entrevistado A:

De forma positiva, é notário o avanço das comunidades onde a Ascoob tem sua atuação, aquecimento dos comércios locais, desenvolvimento sócio econômico tanto no meio rural como urbano existe pessoas que sem a Ascoob jamais conseguiriam adentra ao sistema financeiro por isso que um dos lemas do sistema Ascoob é a inclusão financeira.

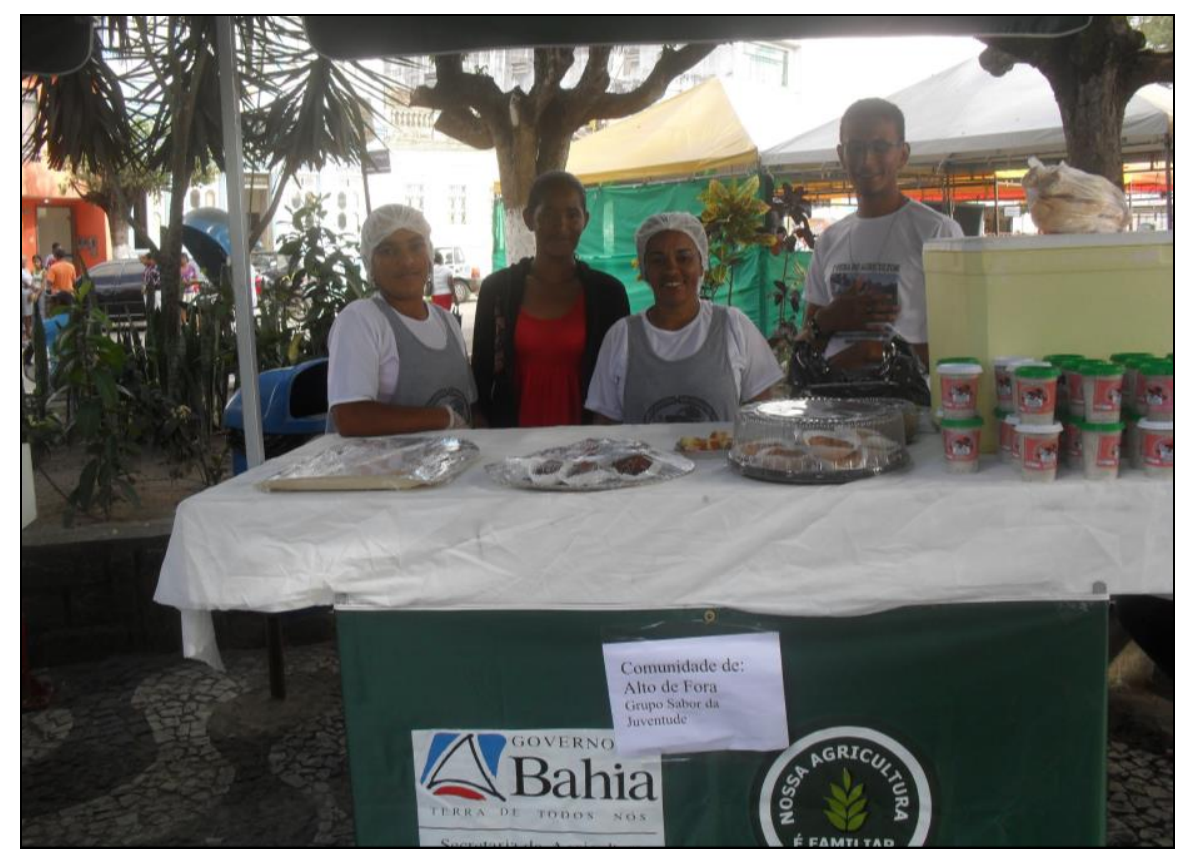

Figura 4: Grupo de produção da ACMPAF em feira regional da agricultura familiar Fonte: ACMPAF, 2015. 
Nas entrevistas realizadas com os dirigentes de associações percebeu se que veem a ASCOOB como algo positivo para as entidades, pois para eles os bancos privados não dão suporte e nem valorizam o trabalho local. Veja-se o que diz o entrevistado B: “Ah, Ascoob a gente vê que é diferente[...]incentiva a produção de produtos como o artesanato feito do sisal, oferece cursos sobre associativismo para os nossos sócios e também tem os técnicos do microcrédito. Nos outros bancos não é assim!"

No que tange a atuação da Ascoob e a maneira como ela é vista pelos seus usuários percebese na entrevista com um dos representantes da ACMPAF, que a visão é bem semelhante à dos dirigentes da ASCOOB. Leia-se o que diz o entrevistado C:

O trabalho da ASCOOB é extremamente importante e tem contribuído para o fortalecimento das organizações comunitárias e para o desenvolvimento local. A nossa associação é filiada como pessoas jurídica, nos sentimos parceiros, devido a facilidade no oferecimento dos serviços e a relação entre associado e cooperativa que é muito diferente do que se fosse em um banco.

Em relação ao fortalecimento dos laços de identidade local é percebível a importância da cooperativa nas relações que são tecidas dentro da ACMPAF. Como ilustra o relato do entrevistado C:

Acho que as políticas da ASCOOB de certo modo têm essa finalidade, contribuir para que o associado, seja ele agricultor ou não, permaneça no seu local com dignidade e com mais qualidade de vida. Através da Assistência técnica que são prestados aos associados, os cursos de geração de renda e cursos para os diretores da associação através do Departamento de Educação Cooperativista.

Partindo do que foi relatado nas entrevistas, apreende-se que as relações tecidas no âmbito do território são fortalecidas pela atuação da ASCOOB, a qual torna - se um importante ator para o fortalecimento da identidade local.

\section{CONSIDERAÇÕES FINAIS}

Ao longo deste artigo buscou-se evidenciar de que maneira o cooperativismo de crédito solidário contribui para o fortalecimento da identidade territorial, através das relações que são engendradas por meio da ASCOOB.

Através das considerações trazidas no decorrer deste trabalho pode-se afirmar que o cooperativismo de crédito solidário, por meio da ASCOOB-Serrinha tem papel fundamental nas interações sociais que acontecem no território do sisal, principalmente aquelas vinculadas à agricultura familiar e aos pequenos agricultores. 
Ainda durante a realização dessa pesquisa, percebeu-se o quanto o cooperativismo solidário ainda tem muitos desafios a enfrentar, pois, embora seja um sistema que vai de encontro às práticas capitalistas comuns, muitas vezes como forma de sobrevivência, este se vê obrigado a conviver com a essência mais perversa do capitalismo.

Em meio a essas constatações, verifica se que o cooperativismo é um importante instrumento de inserção social e principalmente de representação identitária. Essas percepções foram possíveis com o auxilio de teorias como as de Souza (2010), Valadares (2005), Haesbaert (2012), Singer (2003), dentre outros que facilitaram a compreensão do fenômeno estudado.

As discussões aqui apresentadas não possuem o intuito de se encerrar com este artigo, mas sim de contribuir para o temário das experiências cooperativas no Brasil e ainda chama a atenção para sua importância no âmbito do território.

\section{REFERÊNCIAS}

ASCOOB, Associação das Cooperativas de Apoio a Economia Familiar. Institucional - quem somos. Disponível em: http://www.sistemaascoob.com.br/quem-somos.php Acesso em 15 de out. 2015.

BAHIA, Decreto 12354, de 25 de agosto de 2010. Institui o Programa Territórios de Identidade e dá outras providências. Disponível em: http://governo-ba.jusbrasil.com.br/ Acesso em 10 de jun. 2015

BRAGA, Elisabeth dos Santos; ABREU, Enid. Uma reflexão acerca da noção de identidade sob o ponto de vista de Elias e Bourdieu. In: BASTOS, L.C.; LOPES, L.P.M. (org.) Estudos de identidade: entre saberes e práticas. Rio de Janeiro: Garamond, 2011.

BRASIL, Ministério da Agricultura, Pecuária e Abastecimento. Evolução do cooperativismo no Brasil: DENACOOP em ação / Ministério da Agricultura, Pecuária e Abastecimento. Brasília: MAPA, 2006. Disponível em: http://sit.mda.gov.br/

Acesso em: 09 de ago. 2014

BÚRIGO, Fábio Luiz. Finanças e Solidariedade: Uma Análise do Cooperativismo de Crédito Rural Solidário no Brasil. Florianópolis: UFSC, 2006. Disponível em http://www.periodicos.ufsc.br/index. php/politica/article/viewFile/11627/10962. Acesso em: 25 de set. 2014.

CARVALHO, Fredson Mileno Bacelar de. Educação cooperativista: a experiência da Ascoobcooperar. Universidade do Estado da Bahia. 2011.

CHIZZOTTI, Antonio. Pesquisa em ciências humanas e sociais. São Paulo: Cortez, 2001.

DUARTE, José Carlos Silveira. Territórios de identidade e multiterritorialidade, paradigmas para a formulação de uma nova regionalização da Bahia. In: V ENECULT - Encontro de Estudos Multidisciplinares em Cultura. Salvador: UFBA, 2009. Disponível em: <http://www.cult.ufba.br/> Acesso em 10 jun. 2015. 
GIOVELLI, Cleusa. Cooperativismo Coacen Faculdade Sorriso - MT, 2012. Disponível em: <http://tabalhosacademicosunicsorriso.blogspot.com.br> Acesso em 15 out. 2015.

HAESBAERT, Rogério. O mito da desterritorialização: Do "fím dos Territórios" à multiterritorialidade. $7^{\mathrm{a}}$ ed. Rio de Janeiro: Bertrand Brasil, 2012.

HAESBAERT, Rogério. O espaço importa: dilemas da construção identitário-territorial na contemporaneidade. In: BASTOS, L.C.; LOPES, L.P.M. (org.) Estudos de identidade: entre saberes e práticas. Rio de Janeiro: Garamond, 2011.

LÉDA, Renato Leone Miranda. Formação e reestruturação regional da Bahia contemporânea: discutindo recortes geográficos e suas periodizações. In: FONSECA, A.A.M.; BRITO, C.; LÉDA,R.L.M.(org.) Dinâmica da reestruturação do espaço local e regional no estado da Bahia. Salvador: JM, 2010.

ORGANIZAÇÃO INTERNACIONAL DO TRABALHO. Promoção das Cooperativas, recomendação 193,2002. Lisboa, 2006. Disponível em: <http://www.oitbrasil.org.br/content/sobrepromo\%C3\%A7\%C3\%A3o-de-cooperativas> Acesso em: 09 ago. 2014

SANTOS, Milton. O espaço dividido. São Paulo: Edusp, 2004.

SANTOS, Milton. et al. Território, Territórios: ensaios sobre ordenamento territorial. 3 ed. Rio de janeiro: Lamparina, 2011.

SILVA, Edna Lúcia da; MENEZES, Estera Muszkat. Metodologia da Pesquisa e Elaboração de Dissertação. Florianópolis: Laboratório de Ensino a Distância da UFSC, 2001.

SINGER, Paul; SOUZA, André Ricardo de, (orgs.). A Economia Solidária no Brasil: A autogestão como resposta ao desemprego. São Paulo: Contexto, 2003.

SINGER, Paul. Economia solidária: entrevista[abril de 2008]. São Paulo: Estudos avançados. Entrevista concedida a Paulo de Salles Oliveira. Disponível em: <http://www. revistas.usp.br/eav/article/viewFile/10335/12013> Acesso em 20 jul. 2015.

SOUZA, Marcelo L. O território: sobre espaço e poder, autonomia e desenvolvimento. In: CASTRO, Iná E. ; GOMES, Paulo C. C. e CORREAA, Roberto L. (orgs.). Geografia: conceitos e temas. Rio de Janeiro: Bertrand Brasil, 1995.

SPÓSITO, Eliseu Savério. Geografia e Filosofia: contribuição para o ensino do pensamento geográfico. São Paulo: Editora UNESP, 2004.

VAlADARES, J.H. Teoria Geral do Cooperativismo. Viçosa, MG: UFV. Pós-Graduação em Cooperativismo, 2005. 